\title{
Human Mesenchymal Stromal Cells (MSCs) Reduce Neointimal Hyperplasia in a Mouse Model of Flow-Restriction by Transient Suppression of Anti-Inflammatory Cytokines
}

\author{
Makoto Shoji ${ }^{1,2}$, Adam Oskowitz ${ }^{1}$, Christopher D. Malone ${ }^{1}$, Darwin J. Prockop ${ }^{1,3,4}$, \\ and Radhika Pochampally ${ }^{1,5}$ \\ ${ }^{1}$ Center for Gene Therapy, Tulane University Health Sciences Center, New Orleans, LA, U.S.A \\ ${ }^{2}$ Department of Medicine, Division of Cardiology, Showa University School of Medicine, Tokyo, Japan \\ ${ }^{3}$ Department of Biochemistry, Tulane University Health Sciences Center, New Orleans, LA, U.S.A \\ ${ }^{4}$ Texas A\&M Health Science Center College of Medicine Institute for Regenerative Medicine at Scott \&White, Temple, TX, U.S.A \\ ${ }^{5}$ Department of Pharmacology, Tulane University Health Sciences Center, New Orleans, LA, U.S.A
}

\begin{abstract}
Aim: Mesenchymal stromal cells from human bone marrow (hMSCs) were observed to produce therapeutic benefits in some models for cardiac and vascular injuries but their mode of action was not defined. We tested the effects of hMSCs in models for restricted vascular flow.

Methods: We made model for restricted vascular flow produced by permanent ligation of a carotid artery and injected hMSCs to clarify the effects of hMSCs to vascular lesions.

Results: Seven, 14, and 28 days after infusion of hMSCs into the cardiac left ventricle of the mice, there was a significant reduction in neointimal hyperplasia $(p<0.05)$. Seven days after administration of the hMSCs, macrophages infiltration into the ligated artery and serum levels of monocyte chemoattractive protein-1 (MCP-1/CCL-2) $(p<0.05)$ were reduced. However, no hMSCs were detected in the lesions by sensitive PCR assays. We then observed that the serum level of MCP-1 was a potential biomarker for the therapeutic effects of hMSCs in a mouse model for high-fat-diet.

Conclusions: These results indicated the administration of hMSCs decreased the initial and excess inflammatory responses to carotid artery ligation. The decrease in inflammatory response apparently decreased the subsequent neointimal hyperplasia.
\end{abstract}

JAtheroscler Thromb, 2011; 18:464-474.

Key words; Stem/progenitor cells, Mesenchymal stem cells, MCP-1, Cellular engraftment, Biomarker

\section{Introduction}

Surgical manipulation or artherosclerotic damage to arteries frequently causes denudation of the endothelium lining the intima of arteries that activates an

Address for correspondence: Darwin J. Prockop, Texas A\&M Health Science Center College of Medicine Institute for Regenerative Medicine at Scott\&White, 5702 Airport Road, Module C, Temple, TX 76502, U.S.A

E-mail: prockop@medicine.tamhsc.edu

Address for correspondence: Makoto Shoji, Center for Gene Therapy, Tulane University Health Sciences Center, New Orleans, LA 70112, U.S.A

E-mail: mashoji@hotmail.com

Received: June 22, 2010

Accepted for publication: December 21, 2010 inflammatory cascade, causing the proliferation of smooth muscles ${ }^{1)}$. The result is neointimal hyperplasia that reduces blood flow. Therefore, protection of the endothelium and the regulation of inflammatory responses are important for the treatment of arterial insults and manipulations $s^{2,3)}$.

Human adult stem/progenitor cells from bone marrow, referred to as mesenchymal stem cells or multipotent mesenchymal stromal cells (hMSCs), are of interest as potential therapeutic agents because they are easily isolated and expanded, and are capable of differentiating into multiple lineages ${ }^{4)}$. The cells can migrate to engraft into injured tissues, and secrete a large number of cytokines ${ }^{5-7)}$; therefore, use of MSCs as a potential therapeutic option to repair injured arteries is considered $^{8,9)}$. 
Several reports indicate that administration of MSCs modulated re-endothelialization and inhibited arteriosclerotic changes by decreasing the proliferation of smooth muscle cells either by limiting tissue damage or by MSCs differentiating to endothelial cells $\left.^{8,} 10,11\right)$. In contrast, one report indicated that MSCs aggravated postangioplasty aortic restenosis in rats ${ }^{12)}$; however, none of the reports established the mode of action of the MSCs.

In the present study, we first demonstrated that hMSC administration inhibited neointimal hyperplasia in a carotid artery ligation model, apparently by decreasing the initial inflammatory response to the lesion. Next, we observed the serum level of monocyte chemoattractive protein-1 (MCP-1/CCL-2) as a potential biomarker for the therapeutic effects of hMSCs in a mouse model of a high-fat diet.

\section{Method}

\section{Preparation of Cells}

hMSCs from normal healthy donors were obtained from the Tulane Center for the Preparation and Distribution of Adult Stem Cells (http://www. som.tulane.edu/gene_therapy/distribute.shtml). The hMSCs are now available from mscs@medicine.tamhsc. edu and were prepared as previously described ${ }^{13)}$ with protocols approved by the Institutional Review Board. In brief, bone marrow aspirates were taken from the iliac crest of healthy adult donors. Nucleated cells were isolated using a density gradient (Ficol-Paque; Amersham Pharmacia Biotech, Milwaukee, WI, USA) and resuspended in complete hMSC medium: $\alpha$-MEM (GIBCO/BRL, Grand Island, NY, USA); 20\% FBS (lot selected for rapid growth; Atlanta Biologicals, Norcross, GA, USA); 100 units/mL penicillin (GIBCO/BRL); $100 \mu \mathrm{g} / \mathrm{mL}$ streptomycin (GIBCO/ $\mathrm{BRL})$; and $2 \mathrm{mM}$ L-glutamine (GIBCO/BRL). Cells $\left(4\right.$ to $13 \times 10^{7}$ ) were then plated in $20 \mathrm{~mL}$ medium in a $180-\mathrm{cm}^{2}$ culture dish and incubated at $37^{\circ} \mathrm{C}$ with $5 \%$ humidified $\mathrm{CO}_{2}$. After 24 hours, nonadherent cells were removed. Adherent cells were washed twice with phosphate-buffered saline (PBS, $\mathrm{pH}$ 7.2) and incubated with fresh medium. After 5 to 7 days, the cells were harvested with $0.25 \%$ trypsin/ $1 \mathrm{mM}$ EDTA for about $5 \mathrm{~min}$ at $37^{\circ} \mathrm{C}$ and then replated at approximately 3 to 100 cells $/ \mathrm{cm}^{2}$ in an inter-connecting flask system (Cell Factory; Nunc, Rochester, NY, USA). When the cultures reached $70 \%$ confluence, the cells (passage-1) were harvested with trypsin/EDTA, resuspended at $1 \times 10^{6}$ cells $/ \mathrm{mL}$ in $\alpha$-MEM with $5 \%$ dimethyl sulfoxide and 30\% FBS, frozen in 1-mL aliquots overnight at $-80^{\circ} \mathrm{C}$, and then stored in liquid nitrogen. For cell expansion, a frozen vial of passage-1 hMSCs was thawed, plated in $25 \mathrm{~mL}$ complete hMSC medium in a $180-\mathrm{cm}^{2}$ culture dish (Nunc), and incubated at $37^{\circ} \mathrm{C}$ with $5 \%$ humidified $\mathrm{CO}_{2}$. After 24 hours, the medium was removed and adherent, viable cells were washed twice with PBS, harvested with $0.25 \%$ trypsin/ $1 \mathrm{mM}$ EDTA, and replated at 100 cells $/ \mathrm{cm}^{2}$ in hMSCs medium and incubated with a medium change every 3-4 days. The cells (passage-2) were incubated until they reached $70 \%$ confluence (approximately 7 days), at which time they were harvested with trypsin/EDTA. The hMSCs were expanded again as above and used here as $\mathrm{P} 3$ cells. For transplantation, the harvested P3 cells were washed with PBS, centrifuged and resuspended in Hank's balanced salt solution (HBSS) or PBS at $1 \times 10^{6} / 150 \mu \mathrm{L}$ (about 6,700 cells $/ \mu \mathrm{L}$ ). The epitope profile of cells from both passages was essentially the same: negative for hematopoietic markers (CD34, CD36, CD117, and CD 45), and positive for CD29 (95\%), CD44 (>93\%), CD49c (99\%), CD49f (>70\%), CD59 $(>99 \%)$, CD90 (>99\%), CD105 (>99\%), and CD166 (>99\%).

\section{Flow-Restriction Vascular Injury}

All experiments conformed to the Guide for the Care and Use of Laboratory Animals published by the US National Institute of Health, and all animal protocols were approved by the Animal Care and Use Committee of Institutional Tulane University Health Sciences Center. Eight- to ten-week-old male Balb/c Sclnu/nu mice, weighing between 20 and $25 \mathrm{~g}$, were purchased from Jackson Laboratory (Bar Harbor, ME, USA). The experimental protocol was as previously reported ${ }^{14)}$. The mice were anesthetized with a solution of ketamine $(80 \mathrm{mg} / \mathrm{kg}$; Fort Dodge Laboratories, Inc. Sligo, Ireland) and xylazine ( $5 \mathrm{mg} / \mathrm{kg}$; Lloyd Laboratories Walnut, CA, USA) injected intraperitoneally. A flow-restriction vascular injury was caused by ligating the bifurcation of the left common carotid artery. The distal left common carotid artery and its bifurcation into the external and internal carotid arteries were exposed using minimal dissection. The common carotid artery was completely ligated just proximal to the bifurcation with a 6-0 silk suture. All animals recovered and showed no symptoms of a stroke. Immediately, 6 days, and 13 days after ligation, the mice were anesthetized with a solution of ketamine $(80$ $\mathrm{mg} / \mathrm{kg})$ and xylazine $(5 \mathrm{mg} / \mathrm{kg})$ injected intraperitoneally, and injected into the cardiac left ventricle with either $150 \mu \mathrm{L}$ HBSS (HBSS group) or $10^{6} \mathrm{hMSCs}$ in $150 \mu \mathrm{L}$ HBSS (hMSC group). Mice were sacrificed using intraperitoneal administration of an overdose of 

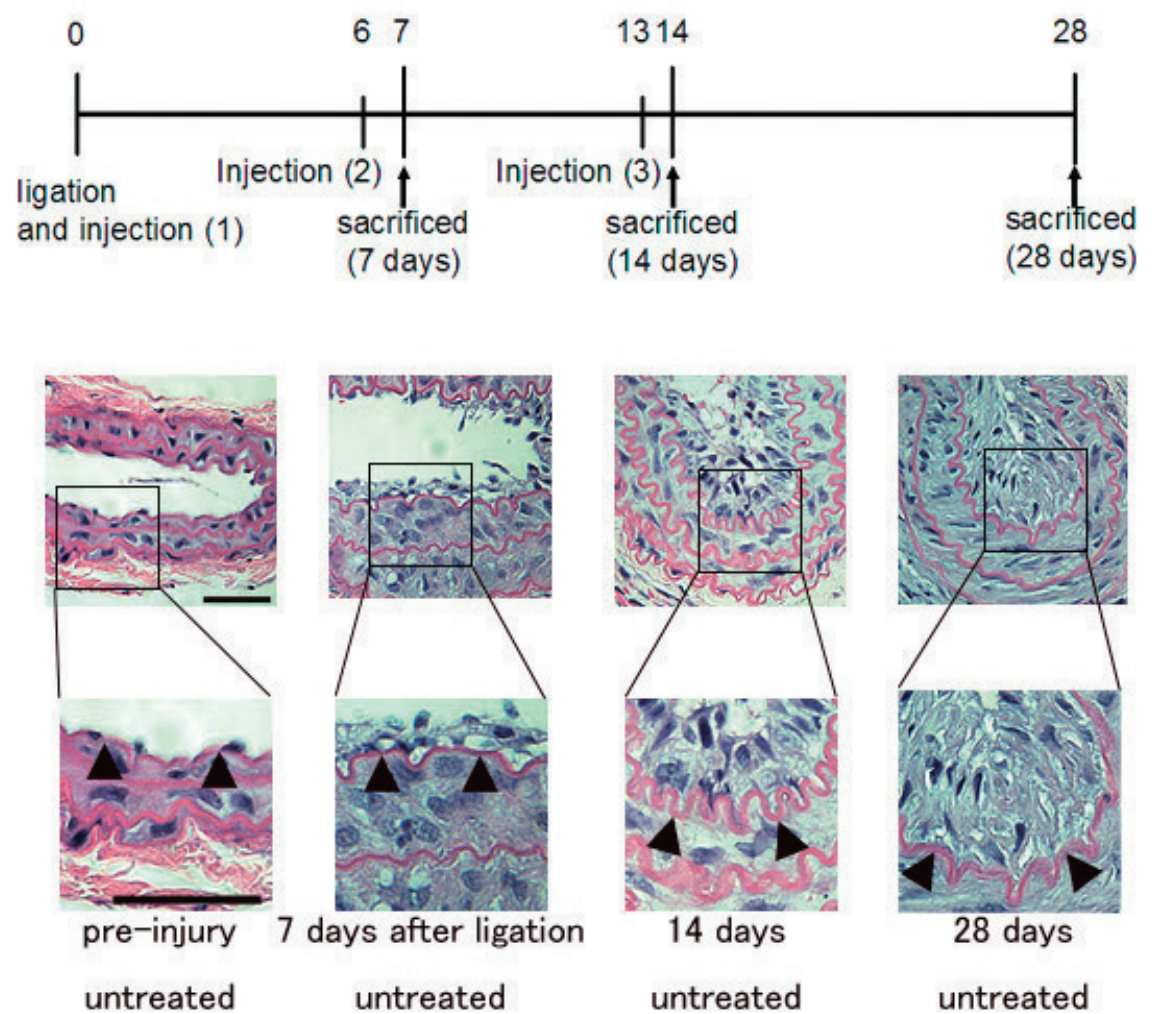

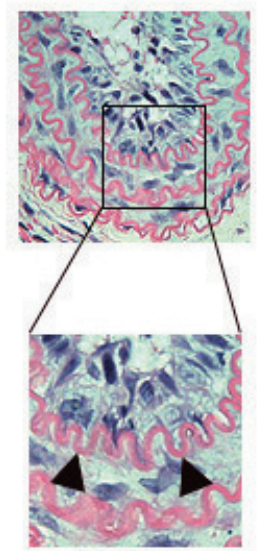

14 days

untreated

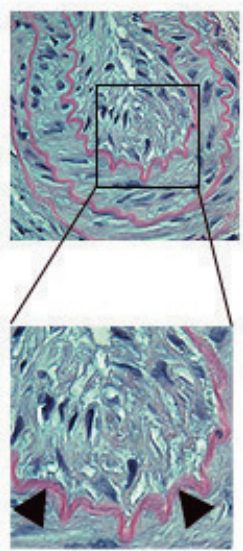

28 days

untreated

Fig. 1. Time course of carotid artery ligation model.

Immediately, 6 days, and 13 days after carotid ligation, the mice were injected into the cardiac left ventricle with either $150 \mu \mathrm{L}$ HBSS or $10^{6}$ hMSCs in $150 \mu \mathrm{L}$ HBSS. Mice were sacrificed at 7,14 and 28 days.

Neointimal hyperplasia continued to increase for up to 28 days after ligation.

Transverse sections were stained with hematoxylin-eosin.

Bar: $20 \mu \mathrm{m}$. Arrowheads indicate internal elastic lamina (IEL).

pentobarbital $(250 \mathrm{mg} / \mathrm{kg})$ at 7,14 and 28 days $(n=5$ to 6 in each group) (Fig. 1). At the time of sacrifice, blood was collected from the right cardiac ventricle to obtain serum for ELISA. The mice were then perfused with $0.9 \% \mathrm{NaCl}$ solution, followed by perfusion fixation with $4 \%$ paraformaldehyde in PBS ( $\mathrm{pH} 7.4$ ). The carotid arteries were carefully excised, fixed in $4 \%$ paraformaldehyde overnight $4{ }^{\circ} \mathrm{C}$, and embedded in paraffin. Cross sections $(5 \mu \mathrm{m})$ were stained with hematoxylin and eosin or Masson trichrome for morphometric analysis.

\section{High-fat Diet Model}

Six- to eight-week-old male Balb/c Scl-nu/nu mice, weight between 20 and $25 \mathrm{~g}$, were purchased from Jackson Laboratory. Mice were placed on a highfat "western-type" diet for 12 weeks ${ }^{15)}$. The western diet consisted of $42 \%$ of total calories from fat and $0.15 \%$ of cholesterol. At 12 weeks, the mice were anesthetized by an intraperitoneal injection of 50 $\mathrm{mg} / \mathrm{kg}$ ketamine and $5 \mathrm{mg} / \mathrm{kg}$ xylazine solution and were injected into the left ventricle of the heart with either $150 \mu \mathrm{l}$ PBS $(n=16)$ or $10^{6}$ hMSCs in $150 \mu \mathrm{L}$ PBS $(n=16)$. For the detection of the inflammatory cytokines in mouse serum, blood was collected from the vascular bundle located at the rear of the jaw bone using a needle (Goldenrod Animal Lancets; MEDIpoint, Inc., Mineola, NY, USA) before and 24 hours after administration of either PBS or hMSCs (Fig. 2). Serum from four mice in each group of 16 mice was pooled into one sample and assayed using ELISA.

\section{Immunohistochemistry}

Paraffin-embedded tissue sections were deparaffinized, incubated with $0.3 \%$ hydrogen peroxide in methanol for $10 \mathrm{~min}$, and blocked with $5 \%$ horse serum for $5 \mathrm{~min}$. Next, the sections were incubated with an anti-mouse macrophage antibody (F4/80; 


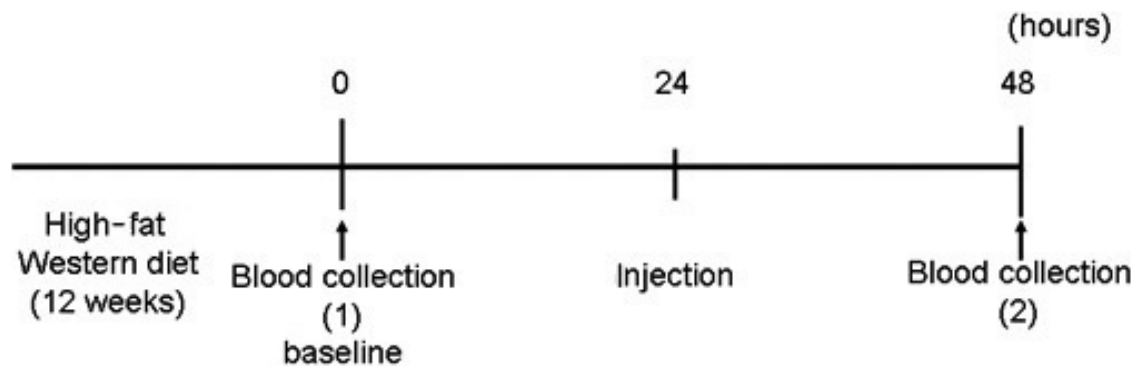

Fig. 2. Time course of high-fat diet model.

Mice were placed on a high-fat "western-type" diet for 12 weeks and injected into the left ventricle of the heart with either $150 \mu \mathrm{L}$ PBS or $10^{6}$ hMSCs in $150 \mu \mathrm{L}$ PBS. Blood was collected before and 24 hours after administration of either PBS or hMSCs.

AbD Serotec, Raleigh, NC, USA) or $\alpha$-smooth muscle actin antibody (SMA) (1A4; DAKO, Carpinteria, CA, USA) for 1 hour at room temperature in a moisture chamber. The slides were incubated with Alexa 488-labeled goat anti-mouse IgG (green; Molecular Probes, Eugene, OR, USA; 1:400 dilution) as the secondary antibody for $90 \mathrm{~min}$ with shading from light. Negative controls used non-immune serum instead of the primary antibody. The nuclei were stained with DAPI $(1: 10000)$. Sections were observed with a fluorescence light microscope (Olympus, Tokyo, Japan).

For detection of human cells, the Vectastain Elite ABC system (Vector Laboratories, Burlingame, CA, USA) was used. Paraffin-embedded tissue sections were deparaffinized, incubated with $0.3 \%$ hydrogen peroxide in methanol for $10 \mathrm{~min}$, blocked with $5 \%$ horse serum, and incubated with anti-human nuclei antibody (235-1; Millipore, Billerica, MA, USA) for 1 hour at room temperature in a moisture chamber. The slides were washed with PBS, and incubated with biotinylated secondary antibodies (1:2,000; Vector Laboratories) for $10 \mathrm{~min}$ followed by avidin-biotin horseradish peroxidase. The sections were visualized with diamiobenzidine substrate.

\section{Histological Analysis}

Morphometric analysis of the sections was performed as previously described ${ }^{16-18)}$. Blocks of the arteries were cut into $5 \mu \mathrm{m}$ transverse sections and stained with hematoxylin-eosin. Four different sections from 5 to 6 animals in each group were digitized to trace the entire lumen, the internal elastic lamina, and external elastic lamina using Image $\mathrm{J}$ image analysis software (NIH image). The intima/media ratio was averaged for each artery.

The ratio of anti-macrophage antibody-positive cells to all DAPI-positive nucleus cells in the neointima after vascular ligation was measured by count- ing the number of neointimal cells with DAPI-stained nuclei. The cells were counted on four F4/80-stained sections visualized under high-power magnification from each of the 5 to 6 animals in each group.

\section{hAlu Real-Time PCR Analysis}

Seven, 14, and 28 days after carotid artery ligation, the mice were sacrificed and bilateral carotid arteries, liver, spleen, and lung were carefully isolated. The tissues were snap-frozen in liquid nitrogen and stored at $-80^{\circ} \mathrm{C}$. Genomic DNA from artery samples was extracted ( $n=5$ to 6 in each group; DNeasy; Qiagen, Valencia, CA, USA), and total DNA was assayed by UV absorbance. Real-time PCR was performed with 50 ng target DNA, human Alu-specific primers, and a fluorescent probe ${ }^{19)}$ on an automated instrument (Model 7700; Applied Biosystems, Foster City, CA, USA). The primers were: Alu forward, 5'-CAT GGT GAA ACC CCG TCT CTA-3'; Alu reverse, 5'GCC TCA GCC TCC CGA GTA G-3'; Probe, 5'FAM-ATT AGC CGG GCG TGG TGG CGTAMRA-3' (Integrated DNA Technologies, Coralville, IA, USA). Standard curves were prepared by adding $1 \times 10^{2}$ to $2.5 \times 10^{4} \mathrm{hMSCs}$ to samples of the carotid arteries, liver, spleen, lung from uninjured mice. All assays were performed in triplicate.

\section{ELISAs}

Serum was assayed using ELISA specific for mouse MCP-1, MCP-3, CRP and VCAM-1 (R \& D Systems, Minneapolis, MN, USA). Quantification was performed by measuring absorbance at $450 \mathrm{~nm}$ and then subtracting out baseline absorbance at 540 $\mathrm{nm}$ using an automated plate reader (Fluostar Optima; BMG Labtech Inc. Cary, NC, USA). Standard curves were generated using recombinant mouse MCP-1, MCP-3, CRP and VCAM-1 (R \& D Systems). 

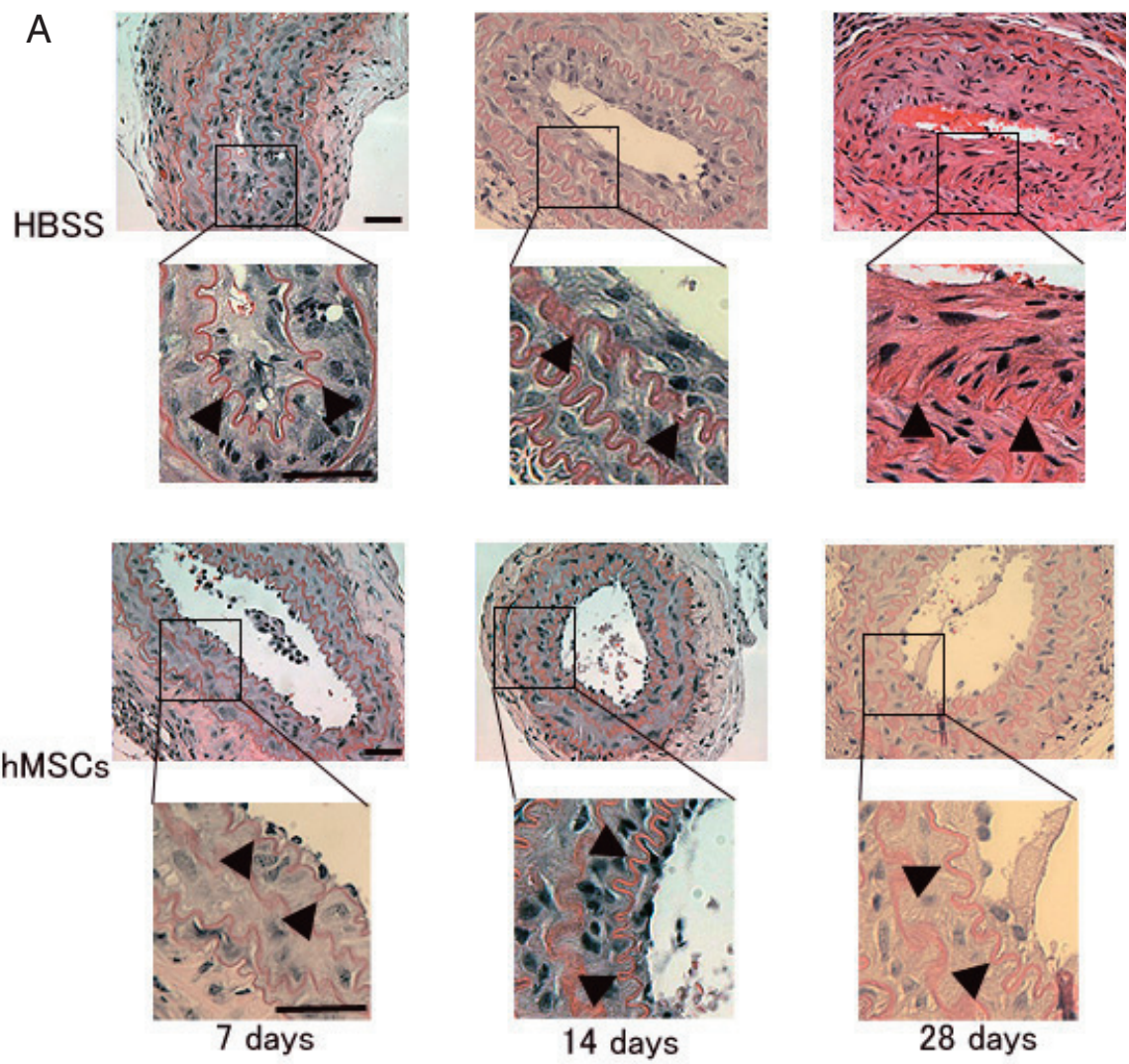

B
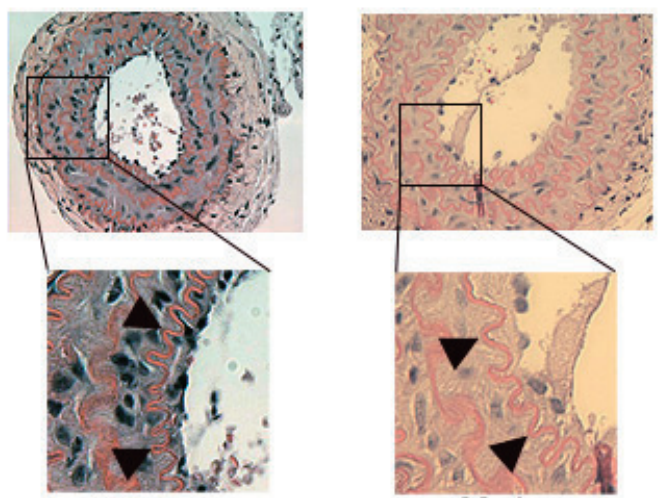

28 days

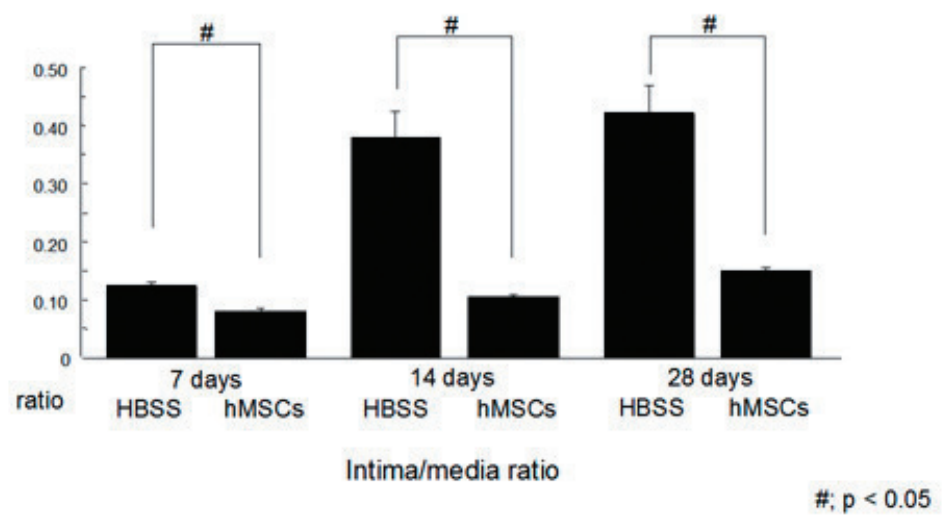

Fig. 3. Inhibition of neointimal hyperplasia by hMSCs administration after vascular ligation.

(A) hMSC administration inhibited neointimal hyperplasia after vascular ligation. (B) The intima/media ratio of the carotid arteries was calculated after vascular ligation. The neointimal area was significantly smaller in the hMSC-treated group than in the control group throughout the experiment $(p<0.05)$.

Upper panels: low magnification, lower panels: high magnification.

Transverse sections were stained with hematoxylin-eosin.

Bar: $20 \mu \mathrm{m}$. Arrowheads indicate IEL.

\section{Statistical Analysis}

All data are expressed as the mean \pm SE. Statistical comparisons were made using Student's $t$-test for unpaired samples. $P<0.05$ was considered significant.

\section{Results}

Administration of MSCs Decreased Neointimal Hyperplasia After Carotid Artery Ligation

First, we confirmed the time course of neointi- 
A
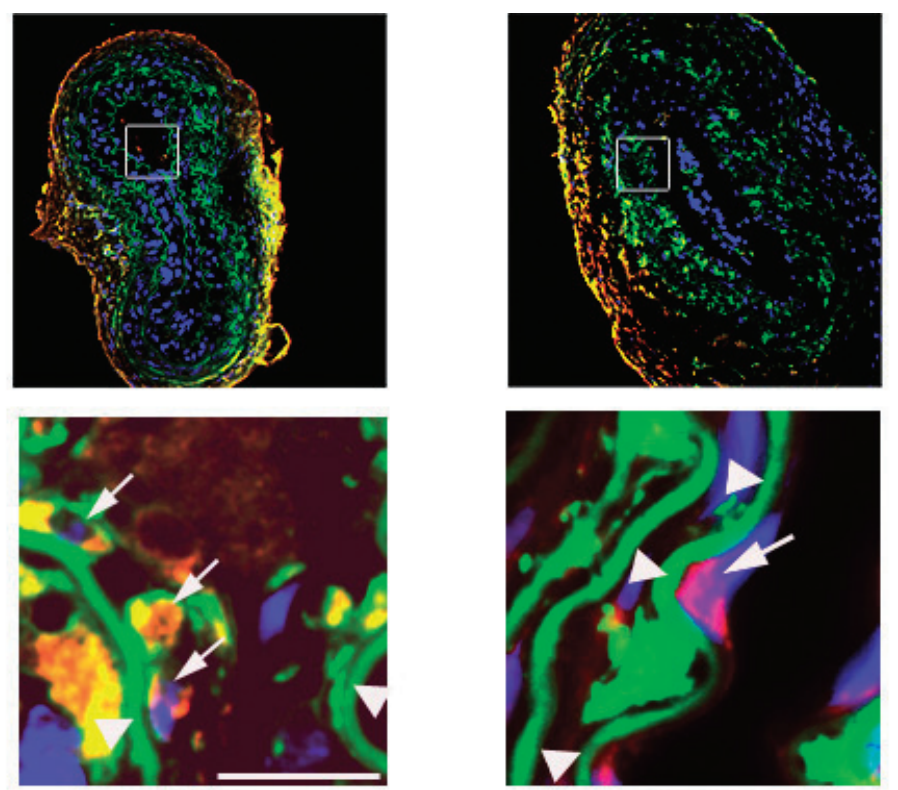

HBSS

hMSCs

B

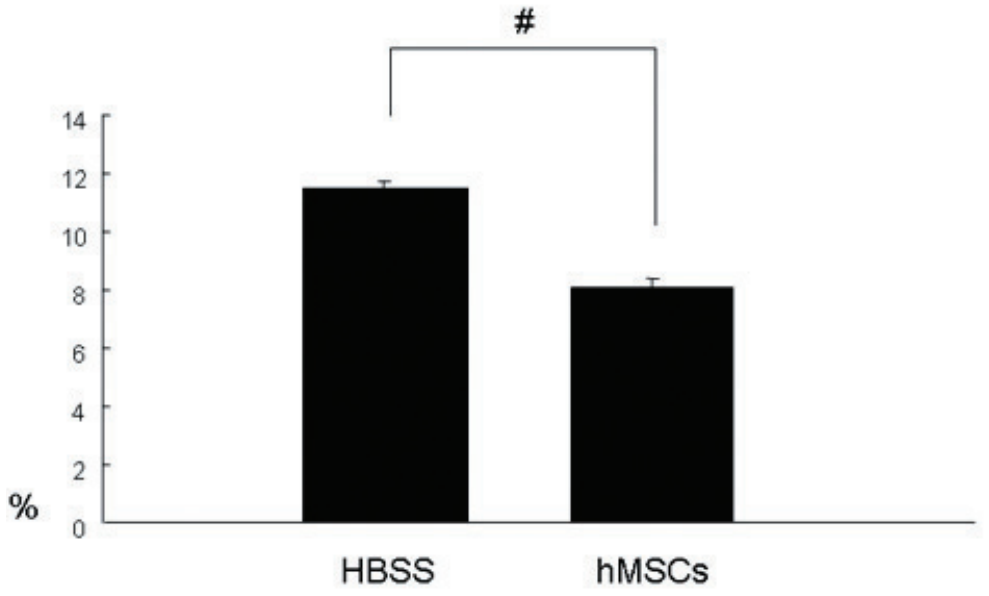

F4/80-positive cells in neointima

$$
\# ; p<0.05
$$

Fig. 4. Inhibition of macrophages in neointima by hMSC administration after carotid artery ligation.

(A) hMSC administration decreased the number of $\mathrm{F} 4 / 80$ positive-inflammatory cells accumulating in neointima 7 days after vascular ligation. Red cells were positive for F4/80 antibody. Green cells were positive for $\alpha$-SMA and blue is DAPI. (B) We calculated the number of F4/80-positive cells accumulating in the neointima of ligated arteries 7 days after vascular ligation. Significantly fewer inflammatory cells were found in hMSC-treated samples than in the control $(p<0.05)$.

Upper panels: low magnification, lower panels: high magnification.

Bar: $20 \mu \mathrm{m}$. Arrow indicates F4/80-positive cells. Arrowheads indicate IEL.

mal hyperplasia after carotid artery ligation in the mouse model. Neointimal hyperplasia continued to increase for up to 28 days after ligation (Fig. 1) as previously described ${ }^{15}$. Next, to detect the efficacy of
hMSC injection, the intima/media ratio was assayed in the model. At 7 days after ligation, neointimal hyperplasia was much less in the hMSC group (intima/media ratio $0.081 \pm 0.004, n=6$ ) than in the 


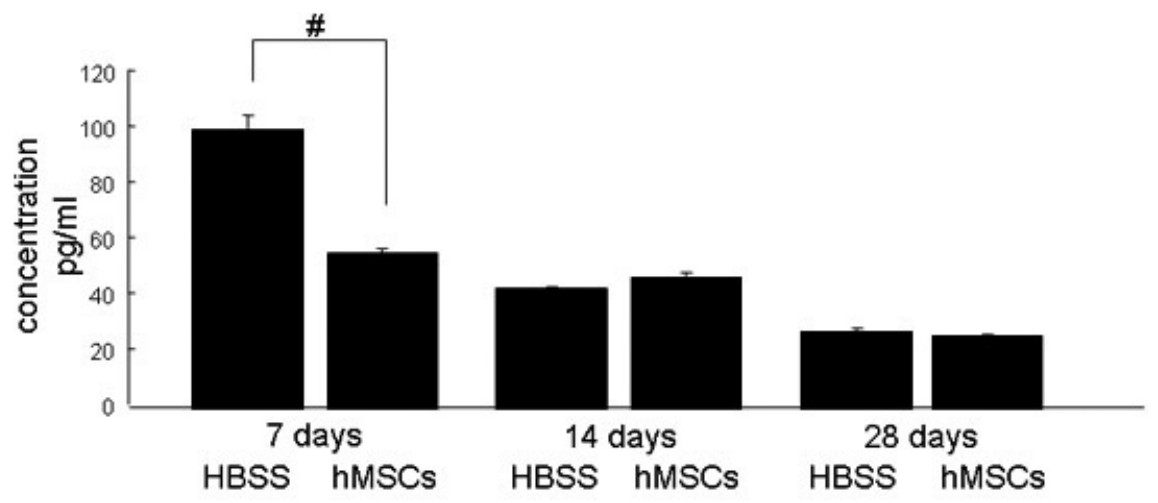

$\# ; p<0.05$

Fig. 5. Serum MCP-1 after ligation of the left common carotid artery.

hMSC administration clearly inhibited the expression of MCP-1 in mouse serum in the early phase. The concentration of MCP-1 protein was significantly lower in the hMSC-treated group than in the control group 7 days after ligation $(p<0.05)$. There were no significant differences in each group 14 and 28 days after ligation. ${ }^{\#} p<0.05$ vs. HBSS injection as a control.

HBSS group (intima/media ratio $0.123 \pm 0.006, n=5$, $p<0.05$ ) (Fig. 3A, B). Neointimal hyperplasia was increased in the control at 14 and 28 days but continued to be lower in the hMSC-treated group. The values at 14 days were $0.104 \pm 0.003(n=6)$ in the hMSC-treated group vs. $0.379 \pm 0.045$ in the control $(n=6, p<0.05)$. At 28 days, the values were $0.149 \pm$ 0.006 vs. $0.423 \pm 0.048(n=5$, respectively, $p<0.05)$.

\section{hMSCs Decrease Neointimal Hyperplasia without Significant Long-Term Engraftment}

To determine whether hMSCs engrafted into the vascular lesion, DNA extracted from the ligated carotid arteries was assayed with a sensitive real-time PCR assay for human $A l u$ sequences $(\mathrm{h} A l u)$. Standard curves were prepared by adding $1 \times 10^{2}$ to $2.5 \times 10^{4}$ hMSCs to samples of carotid arteries from uninjured mice as previously described ${ }^{16)}$ (standard curve liner regression; $y=-0.2902 x+8.6088, R^{2}=0.9981$; supplemental figure). No significant Alu sequences were detected in $50 \mathrm{ng}$ DNA assayed 7, 14, and 28 days after ligation in mice administered hMSCs. Assuming an average DNA content of $5 \mathrm{pg}$ per cell, the results indicated that there was less than one human cell per 10,000 cells in the samples. hMSCs were not detected in other organs but in the lung 7 days after ligation $(249.7 \pm 79.9$ cells). In addition, sections of the arteries were assayed by immunohistochemistry using human specific anti-nuclei antibody. Again, no human cells were detected in carotid arteries (supplemental figure).

\section{Administration of hMSCs Decreased Macrophage Infiltration 7 Days After Carotid Artery Ligation}

To evaluate the local inflammatory response, we performed immunohistochemistry in each section from mouse carotid arteries using an antibody to the macrophage marker, F4/80. At 7 days after the injury, F4/80-positive inflammatory cell accumulation on the neointimal hyperplasia was higher in the HBSS group $(11.4 \pm 0.22 \%$ of cells, $n=5)$ than in the hMSC-treated group (8.01 $\pm 0.36 \%, n=6, p<0.05)$ (Fig. 4A, B). At 14 and 28 days, macrophages were rare in both the HBSS and hMSC-treated groups (not shown).

\section{Serum MCP-1 as a Biomarker for the Effects of hMSCs in a Model of Flow Restriction}

We next tested serum MCP-1 as a biomarker for the effects of hMSCs in a mouse model of restricted arterial flow. Seven days after ligation of the left common carotid artery, the serum level of MCP-1 protein was elevated in HBSS mice with ligation and was significantly lower in mice in which hMSCs were infused immediately after surgery and on day $6(100.7 \pm 5.15$ $\mathrm{pg} / \mathrm{mL}, n=5$, vs. $56.1 \pm 1.86 \mathrm{pg} / \mathrm{mL}, n=6, p<0.05)$ (Fig. 5). After 14 and 21 days, the levels decreased in the HBSS group with ligation and there was no difference from the control group that was infused with hMSCs on days 0,6 and $13(43.2 \pm 0.95$ vs. $47.2 \pm$ $1.83, n=6$ and $28.2 \pm 1.02$ vs. $26.3 \pm 0.50, n=5$, respectively, n.s.). 

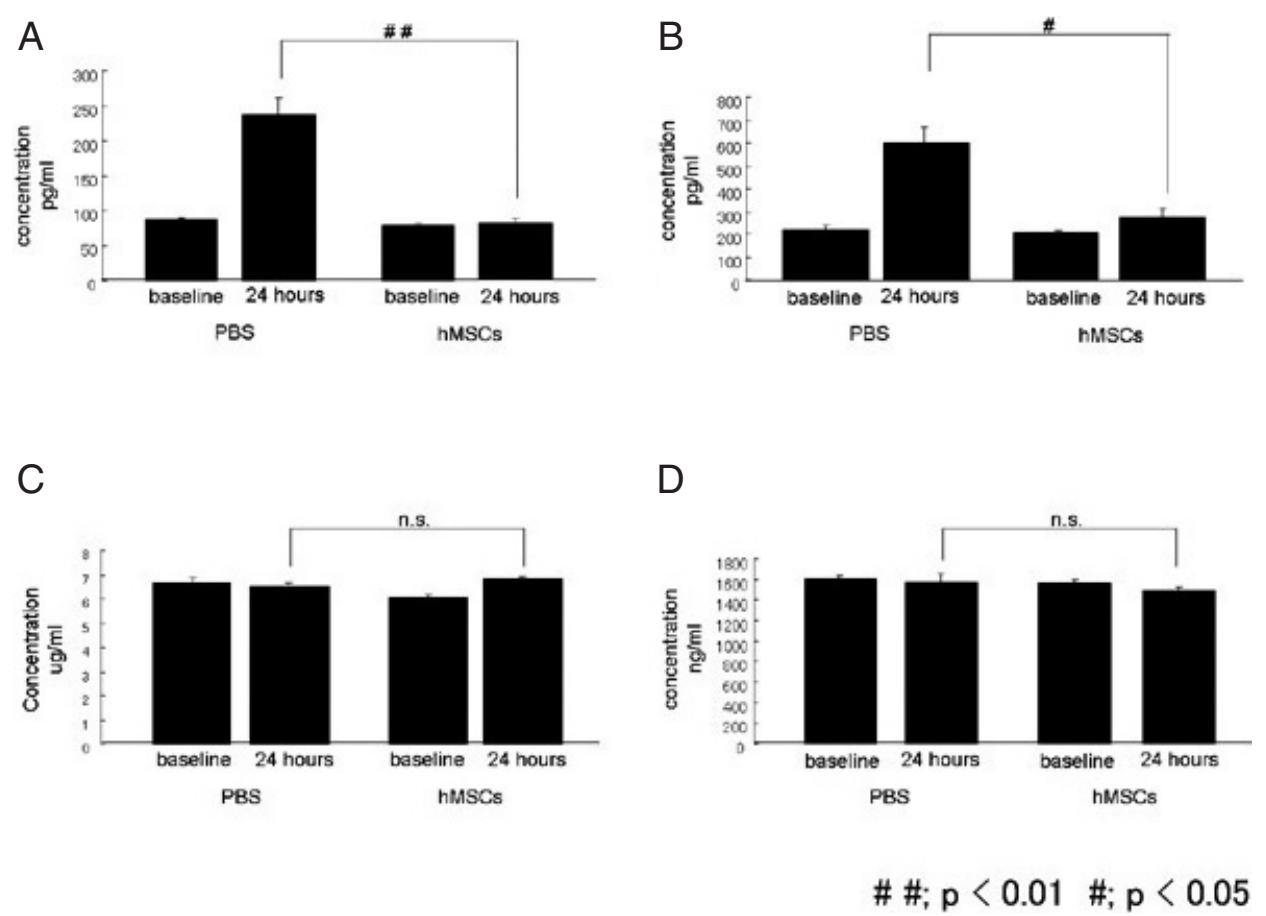

Fig. 6. Inhibition of MCP-1 protein in serum by hMSC administration to mice placed on a high-fat diet.

(A) Serum MCP-1 in mice before (baseline) and 24 hours after administration of hMSCs to mice that had been on the diet for 12 weeks. (B) Serum MCP-3 in the same mice. (C) Serum CRP in the same mice. (D) serum VCAM-1 in the same mice. ${ }^{\# \#} p<0.01 .{ }^{*} p<0.05$.

\section{Biomarker for the Effects of hMSC Administration in the High-fat Model}

In the second experiment, attempts were made to establish a biomarker for the effects of hMSCs in a mouse model of a high-fat diet. For this purpose, $10^{6}$ hMSCs were infused into the cardiac left ventricle of mice that had been fed a high-fat diet for 12 weeks, and the sera were assayed with ELISA to evaluate changes in the inflammatory response (Fig. 2). The level of MCP-1 in mouse serum was not different in each group at baseline and 24 hours before injection (concentration: $87.8 \pm 3.04 \mathrm{pg} / \mathrm{mL}$ in PBS group, 79.8 $\pm 6.96 \mathrm{pg} / \mathrm{mL}$ in hMSCs group, 4 samples, respectively, n.s.). It was higher in mice on the diet for 12 weeks who were injected with PBS 24 hours beforehand $(237.3 \pm 23.7 \mathrm{pg} / \mathrm{mL}, n=4)$ but was lower in mice injected with hMSCs $(80.3 \pm 6.96 \mathrm{pg} / \mathrm{mL}, n=4$, $p<0.01$ ) (Fig. 6A). Moreover, hMSC administration also decreased the serum level of MCP-3 protein. The concentration of MCP-3 protein in mouse serum was not different in each group at baseline $(227.5 \pm 13.9$ $\mathrm{pg} / \mathrm{mL}$ in PBS group, $212.5 \pm 3.76 \mathrm{pg} / \mathrm{mL}$ in hMSC group, 4 samples, respectively, n.s.), but was significantly lower in mice treated with hMSCs (282.3 \pm
$37.6 \mathrm{pg} / \mathrm{mL}$ vs. $602.5 \pm 74.0 \mathrm{pg} / \mathrm{mL}, n=4, p<0.05)$ (Fig. 6B): however, administration of hMSCs did not decrease the serum level of CRP (before $6.7 \pm 0.18$ $\mu \mathrm{g} / \mathrm{mL}$ in PBS group and $6.1 \pm 0.03 \mu \mathrm{g} / \mathrm{mL}$ in hMSC group; after $6.5 \pm 0.16 \mu \mathrm{g} / \mathrm{mL}$ in PBS group and 6.9 $\pm 0.08 \mu \mathrm{g} / \mathrm{mL}$ in hMSC group, $n=4$, n.s.). Also, administration of hMSC did not decrease the serum level of VCAM-1 (before $1612 \pm 20.3 \mathrm{ng} / \mathrm{mL}$ in PBS group and $1558 \pm 44.6 \mathrm{ng} / \mathrm{mL}$ in hMSC group; after $1573 \pm 83.7 \mathrm{ng} / \mathrm{mL}$ in PBS group and $1495 \pm 26.6$ $\mathrm{ng} / \mathrm{mL}$ in hMSC group, $n=4$, n.s.) (Fig. 6C, D).

\section{Discussion}

We indicated that hMSCs reduced neointimal hyperplasia after carotid ligation through the decrease of MCP-1 in mouse serum and inflammation of carotid arteries. Next, we confirmed that MCP-1 might be a potential biomarker which hMSCs could modulate in a model of a high-fat diet.

The present study demonstrated that systemic administration of hMSCs decreased neointimal hyperplasia in a mouse model without significant long-term engraftment of the cells into the lesion. Instead, the 


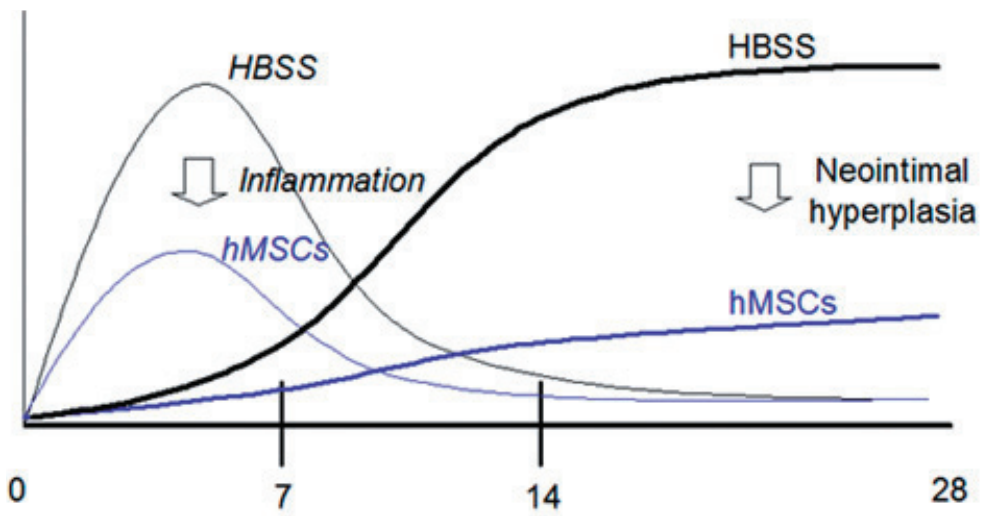

(days)

Fig.7. Schematic illustration of the effects of hMSCs on ligated carotid artery (see Discussion).

therapeutic benefit of the cells was probably explained by the modulation of inflammatory responses (Fig. 7), as demonstrated by decreased macrophage infiltration and serum MCP-1 7 days after ligation of the artery and administration of the cells. Similar reports of therapeutic improvement without significant engraftment of MSCs have now been reported in a number of animal models ${ }^{20-22)}$. The results suggest that the cells have a "touch and go" effect ${ }^{23)}$ by suppressing inflammatory and immune reactions ${ }^{24,25)}$.

The site of the anti-inflammatory actions of hMSCs in many situations is not apparent. In these experiments, the hMSCs were infused into the cardiac ventricle to minimize trapping of the cells in the lung, which occurs after intravenous infusion ${ }^{26-28)}$. This strategy was used previously when administering hMSCs to immunodeficient mice made diabetic by the administration of streptozotocin ${ }^{29)}$; therefore, it is possible that hMSCs transiently engrafted in the arterial lesion to exert their anti-inflammatory effects. However, the decrease of serum MCP-1 raises the possibility that the anti-inflammatory effect was produced by hMSCs that were trapped in the lung or peripheral capillaries and that secreted one or more anti-inflammatory factors.

MCP-1 is an important chemokine that regulates the migration and infiltration of inflammatory cells, such as monocytes/macrophages. The expression of MCP-1 is pro-inflammatory, directly related to the extent of atherosclerotic lesions in arteries. For example, anti-MCP-1 gene therapy limited the progression of established atherosclerosis in an animal vascular injury model ${ }^{30)}$. MCP-3 is a CC chemokine that functions by activating monocytes via the specific chemokine receptor CCR2. It is known that CCR2 is shared with MCP-1, and MCP-3 also plays a role in the pathogenesis of restenosis or atherosclerosis ${ }^{31)}$. We observed that the serum level of MCP-1 was decreased in mouse serum 7 days after administration of hMSCs. Our results also indicated that serum levels of MCP-1 and MCP-3 were significantly decreased 24 hours after hMSC administration in a high-fat diet model. Because MCP-1 has direct proatherogenic properties, in addition to its effects on the amplification of the inflammatory cascade, it could have played a major role in inhibiting neointimal hyperplasia after surgery in this experimental model.

MSCs are widely known to have pleiotropic effects, such as cytoprotection and anti-apoptosis. MSCs produce an anti-immune or immune-suppressive response, consistent with numerous reports that the cells have similar effects in culture, in animal disease models, and in patients with graft-vs.-host disease $^{6,7,32-34)}$. These anti-inflammatory effects are consistent with those in a mouse model of lung injury ${ }^{35,36)}$. Moreover, MSCs also secrete various growth factors, such as nitric oxide, vascular endothelial growth factor, and placental growth factor- $1^{5,37)}$, which regulate vascular remodeling. Taken together, our results suggest that hMSCs could be useful and safe tools for restenosis or atherosclerosis therapy.

At the same time, it is important to note that inconsistent results have been reported with MSCs. For example, one report indicated that hMSCs might increase neointimal hyperplasia through the excessive repair process of the vessel in vivo ${ }^{38)}$. Also, another group reported the unexpected observation that MSCs aggravated plaque stability through the accumulation of inflammatory cells in a rat angioplasty model ${ }^{12)}$. This indicates that hMSCs may accumulate and trans- 
differentiate not only into endothelial progenitor cells, but also putative smooth muscle progenitor cells, resulting in an increased intima-media ratio. The discrepancies with our own results are probably explained by variables in the experimental conditions, such as subtle differences in the animal models, as well as differences in the protocols for preparing and expanding the MSCs in culture. The hMSCs employed in the experiments reported here were prepared with a standardized low-density protocol that provides cultures more enriched for early progenitor cells than the commonly employed confluent cultures. The cells from the low-density cultures express higher levels of epitopes linked to cell motility, are more clonogenic, differentiate more efficiently in vitro, and are less prone to produce lethal emboli after intravenous infusion into mice ${ }^{27}$. Some of the discrepancies in published reports might be resolved by using serum markers for inflammation, such as MCP-1. Serum levels of MCP-1 and other markers should also be useful in monitoring the responses of patients in clinical trials with MSCs.

Our immunohistological data demonstrated that neointimal hyperplasia in the early phase is composed of inflammatory cells without human-derived cells. This suggests that inflammatory cells affect the process of neointimal formation and elevate the intima/ media ratio after carotid artery ligation. Therefore, the inhibition of inflammatory reactions via the endogenous or paracrine effects of hMSC administration may lead to stability of the vascular region and decrease the neointimal portion (Fig.7). A further hypothesis is that hMSCs may mobilize more endogenous stem cells from bone marrow to the peripheral circulation, and the mobilized cells accumulate on the injured side of the vascular luminal where they may modulate both systemic and local inflammatory responses.

In conclusion, the results demonstrated that hMSC administration after ligation of the common carotid artery in mice reduced the initial increase of the serum level of MCP-1 and neointimal proliferation, apparently by reducing the initial excessive inflammatory response. In addition, administration of hMSCs to mice that are a model of a high-fat diet reduced serum levels of two pro-inflammatory proteins, MCP-1 and -3; therefore, the results suggested that serum levels of MCP-1 or -3 might be useful biomarkers for the anti-inflammatory effects of MSCs. The overall effect of hMSCs was to heal the vascular lesion by secreting endogenous and paracrine factors that modulated the inflammatory response without evidence of significant long-term engraftment of the cells.

\section{Acknowledgements}

This work was supported in part by grants from the NIH (P40 RR 17447) and the Louisiana Gene Therapy Research Consortium.

\section{References}

1) Ross R: Atherosclerosis-an inflammatory disease. N Engl J Med, 1999; 340: 115-126

2) Kasai T, Miyauchi K, Yokoyama T, Kajimoto K, Sumiyoshi K, Kubota N, Ikeda E, Daida H: Pioglitazone attenuates neointimal thickening via suppression of early inflammatory response in a porcine coronary after stenting. Atherosclerosis, 2008; 197: 612-619

3) Corrado E, Rizzo M, Coppola G, Fattouch K, Novo G, Marturana I, Ferrara F, Novo S: An update on the role of markers of inflammation in atherosclerosis $\mathrm{J}$ Atheroscler Thromb, 2010; 17: 1-11

4) Prockop DJ: Marrow strome cells as stem cells for nonhematopoietic tissues. Science, 1997; 276: 71-74

5) Fiedler J, Leucht F, Waltenberger J, Dehio C, Brenner RE: VEGF-A and PIGF-1 stimulate chemotactic migration of human mesenchymal progenitor cells. Biochem Biophys Res Commun, 2005; 334: 561-568

6) Ren G, Zhang L, Zhao X, Xu G, Zhang Y, Roberts AI, Zhao RC, Shi Y: Mesenchymal stem cell-mediated immunosuppression occurs via concerted action of chemokines and nitric oxide. Cell Stem Cell, 2008; 2: 141-150

7) Uccelli A, Pistoia V, Moretta L: Mesenchymal stem cells: A new strategy for immunosuppression? Trends Immunol, 2007; 28: 219-226

8) Mirza A, Hyvelin JM, Rochefort GY, Lermusiaux P, Antier D, Awede B, Bonnet P, Domenech J, Eder V: Undifferentiated mesenchymal stem cells seeded on vascular prosthesis contribute to the restoration of a physiologic vascular wall. J Vasc Surg, 2008; 47: 1313-1321

9) Prockop DJ, Gregory CA, Spees JL: One strategy for cell and gene therapy: harnessing the power of adult stem cells to repair tissues. Proc Natl Acad Sci USA, 2003; 100 (Suppl.): 11917-11923

10) Hashi CK, Zhu Y, Yang GY, Young WL, Hsiao BS, Wang K, Chu B, Li S: Antithrombogenic property of bone marrow mesenchymal stem cells in nanofibrous vascular grafts. Proc Natl Acad Sci USA, 2007; 104: 11915-11920

11) Wu X, Huang L, Zhou Q, Song Y, Li A, Jin J, Cui B: Mesenchymal stem cells participating in ex vivo endothelium repair and its effect on vascular smooth muscle cells growth. Int J Cardiol, 2005; 105: 274-282

12) Chen XC, Shan HW, Qu HL, Ge JB, Ge ZP: Bone marrow mesenchymal stem cells transplantation aggravates postangioplasty aortic restenosis in rats. Zhonghua Xin Xue Guan Bin Za Zhi, 2007; 35: 802-806

13) Sekiya I, Larson BL, Smith JR, Pochampally R, Cui JG, Prockop DJ: Expansion of human adult cells from bone marrow stroma: conditions that maximize the yields of early progenitors and evaluate their quality. Stem Cells, 2002; 20: 530-554

14) Sata M, Walsh K: Fas ligand-deficient mice display 
enhanced leukocyte infiltration and intima hyperplasia in flow-restricted vessels. J Mol Cell Cardiol, 2000; 32: 1395-1400

15) Sukhanov S, Higashi Y, Shai SY, Vaughn C, Mohler J, Li Y, Song YH, Titterington J, Delafontaine P: IGF-1 reduces inflammatory responses, suppresses oxidant stress, and decreases atherosclerosis progression in ApoE deficient mice. Arterioscler Thromb Vasc Biol, 2007; 27: 26842690

16) Sata M, Saiura A, Kunisato A, Tojo A, Okada S, Tokuhisa T, Hirai H, Makuuchi M, Hirata Y, Nagai R: Hematopoietic stem cells differentiate into vascular cells that participate in the pathogenesis of atherosclerosis. Nat Med, 2002; 8: 403-409

17) Shoji M, Iso Y, Kusuyama T, Omori Y, Soda T, Tsunoda F, Sato T, Koba S, Geshi E, Kobayashi Y, Katagiri T, Suzuki $\mathrm{H}$ : High-dose granulocyte colony stimulating factor promotes neointimal hyperplasia in the early phase and inhibits neoinimal hyperplasia in the late phase after vascular injury. Circ J, 2008; 72: 1885-1893

18) Sato T, Suzuki H, Shibata M, Kusuyama T, Omori Y, Soda T, Shoji M, Iso Y, Koba S, Geshi E, Katagiri T, Shioda S, Sekikawa K: Tumor-necrosis-factor-alpha-genedeficient mice have improved cardiac function through reduction of intercellular adhesion molecule-1 in myocardial infarction. Circ J, 2006; 70: 1635-1642

19) McBride C, Gaupp D, Phinney DG: Quantifying levels of transplanted murine and human mesenchymal stem cells in vivo by real-time PCR. Cytotherapy, 2003; 5: 7-18

20) Iso Y, Spees JL, Serrano C, Bakondi B, Pochampally R, Song YH, Sobel BE, Delafontaine P, Prockop DJ: Multipotent human stromal cells improve cardiac function after myocardial infarction in mice without long-term engraft. Biochem Biophys Res Commun, 2007; 354: 700-706

21) Prockop DJ: "Stemness" does not explain the repair of many tissues by mesenchymal stem/multipotent stromal cells (MSCs). ClinPharmacol Ther, 2007; 82: 241-243

22) Togel F, Weiss K, Yang Y, Hu Z, Zhang P, Westenfelder C: Vasculotropic, paracrine actions of infused mesenchymal stem cells are important to the recovery from acute kidney injury. Am J Physiol Renal Physiol, 2007; 292: F1626F1635

23) Uccelli A, Pistoia V, Moretta L: Mesenchymal stem cells in health and disease. Nat Rev Immunol, 2008; 8: 726-736

24) Chen FH, Tuan RS: Mesenchymal stem cells in arthritic disease. Arthritis Res Ther, 2008; 10: 223

25) Ohtaki H, Ylostalo JH, Foraker JE, Robinson AP, Reger RL, Shioda S, Prockop DJ: Stem/progenitor cells from bone marrow decrease neuronal death in global ischemia by modulation of inflammatory/immune responses. Proc Natl Acad Sci USA, 2008; 105: 14638-14643

26) Gao J, Dennis JE, Muzic RF, Lundberg M, Caplan AI: The dynamic in vivo distribution of bone marrow-derived mesenchymal stem cells after infusion. Cells Tissues Organs, 2001; 169: 12-20

27) Lee RH, Seo MJ, Pulin AA, Gregory CA, Ylostalo J, Prockop DJ: The CD34-like protein PODXL and alpha6integrin (CD49f) identify early progenitor MSCs with increased clonogenicity and migration to infarcted in mice. Blood, 2009; 113: 816-826

28) Schrepfer S, Deuse T, Reichenspurner H, Fischbein MP, Robbins RC, Pelletier MP: Stem cell transplantation: the lung barrier. Transplant Proc, 2007; 39: 573-576

29) Lee RH, Seo MJ, Reger RL, Spees JL, Pulin AA, Olson SD, Prockop DJ: Multipotent stromal cells from human marrow home to and promote repair of pancreatic islets and renal glomeruli in diabetic NOD/scid mice. Proc Natl Acad Sci USA, 2006; 103: 17438-17443

30) Ohtani K, Usui M, Nakano K, Kohjimoto $Y$, Kitajima $S$, Hirouchi Y, Li XH, Kitamoto S, Takeshita A, Egashira K: Antimonocyte chemoattractant protein-1 gene therapy reduces experimental in-stent restenosis in hypercholesterolemic rabbits and monkeys. Gene Ther, 2004; 11: 12731282

31) Wang $X$, Li X, Yue TL, Ohlstein EH: Expression of monocyte chemostactic protein-3 mRNA in rat vascular smooth muscle cells and in carotid artery after balloon angioplasty. Biochim Biophys Acta, 2000; 1500: 41-48

32) Aggarwal S, Pittenger MF: Human mesenchymal stem cells modulate allogeneic immune cells responses. Blood, 2005; 105: 1815-1822

33) Le Blanc K, Ringden O: Immunomodulation by mesenchymal stem cells and clincal experience. J Inter Med, 2007; 262: 509-525

34) Serhan CN, Chiang N, Van Dyke TE: Resolving inflammation: Dual anti-inflammatory and pro-resolution lipid mediators Nat Rev Immnunol, 2008; 8: 349-361

35) Gupta N, Su X, Popov B, Lee JW, Serikov V, Matthay MA: Intrapulmonary delivery of bone marrow-derived mesenchymal stem cells improves survival and attenuates endotoxin-induced acute lung injury in mice. J Immunol, 2007; 179: 1855-1863

36) Ortiz LA, Dutreil M, Fattman C, Pandey AC, Torres G, Go K, Phinney DG: Interleukin 1 receptor antagonist mediates the antiinflammatory and antifibrotic effect of mesenchymal stem cells during lung injury. Proc Natl Sci USA, 2008; 104: 11002-11007

37) Marrony S, Bassilana F, Seuwen K, Keller H: Bone morphogenetic protein 2 induces placental growth factor in mesenchymal stem cells. Bone, 2003; 33: 426-433

38) Wang CH, Cherng WJ, Yang NI, Kuo LT, Hsu CM, Yeh HI, Lan YJ, Yeh CH, Stanford WL: Late-outgrowth endothelial cells attenuate intimal hyperplasia contributed by mesenchymal stem cells after vascular injury. Arterioscler Thromb Vasc Biol, 2008; 28: 54-60 